\title{
Preservation of iron(II) by carbon-rich matrices in a hydrothermal plume
}

\author{
Brandy M. Toner ${ }^{1 \star}$, Sirine C. Fakra ${ }^{2}$, Steven J. Manganini ${ }^{1}$, Cara M. Santelli ${ }^{1}$, Matthew A. Marcus ${ }^{2}$, \\ James W. Moffett ${ }^{3}$, Olivier Rouxel ${ }^{1}$, Christopher R. German' ${ }^{1}$ and Katrina J. Edwards ${ }^{1,3}$
}

\begin{abstract}
Hydrothermal venting associated with mid-ocean ridge volcanism is globally widespread'. This venting is responsible for a dissolved iron flux to the ocean that is approximately equal to that associated with continental riverine runoff ${ }^{2}$. For hydrothermal fluxes, it has long been assumed that most of the iron entering the oceans is precipitated in inorganic forms. However, the possibility of globally significant fluxes of iron escaping these mass precipitation events and entering open-ocean cycles is now being debated ${ }^{3}$, and two recent studies suggest that dissolved organic ligands might influence the fate of hydrothermally vented metals ${ }^{4,5}$. Here we present spectromicroscopic measurements of iron and carbon in hydrothermal plume particles at the East Pacific Rise mid-ocean ridge. We show that organic carbon-rich matrices, containing evenly dispersed iron(II)-rich materials, are pervasive in hydrothermal plume particles. The absence of discrete iron(II) particles suggests that the carbon and iron associate through sorption or complexation. We suggest that these carbon matrices stabilize iron(II) released from hydrothermal vents in the region, preventing its oxidation and/or precipitation as insoluble minerals. Our findings have implications for deep-sea biogeochemical cycling of iron, a widely recognized limiting nutrient in the oceans.
\end{abstract}

The mixing of hot, chemically reduced hydrothermal fluids with cold, oxygenated deep-sea water drives the dominant inorganic reactions of polymetallic sulphide precipitation and $\mathrm{Fe}$ oxidation and precipitation in plumes ${ }^{6}$. As a consequence of seawater entrainment into rising plumes, the entire volume of the global ocean must, on average, come into contact with hydrothermal fluids and particles in a relatively short time, $4000-8000 \mathrm{yr}$. Much of the trace element chemical reactivity observed in plumes is attributed, but has not been firmly linked, to the precipitation and surface reactivity of $\mathrm{Fe}$ oxyhydroxide minerals in both buoyant and neutrally buoyant plumes ${ }^{7}$. The rate of hydrothermal Fe(II) oxidation has been correlated with the redox state of local deep waters $^{8}$; however, roles for dissolved organic carbon ${ }^{9}$ (DOC) and microbial activity ${ }^{10}$ have also been hypothesized.

Although hydrothermal plume processes influence important global ocean elemental cycles, there is little mechanistic information available about these processes owing to the dynamic character of the plume environment and the complexity of plume particles. Most knowledge of plume mineral composition and reactivity is inferred from either bulk digestion of filtered solids ${ }^{7}$ or scanning electron microscopy with elemental analysis ${ }^{6}$. Here we use synchrotron-based X-ray absorption spectromicroscopy to investigate $\mathrm{Fe}$ and $\mathrm{C}$ speciation at the nanoscale in plume particles. We propose a mechanism for the production of an organic matrix capable of stabilizing hydrothermally vented $\mathrm{Fe}(\mathrm{II})$. Our results suggest that the assumption that Fe cycling in deep-sea hydrothermal plumes is driven solely by inorganic processes is no longer valid and that organic processes must also be considered.

Our spectromicroscopic observations and bulk chemical measurements indicate that organic $\mathrm{C}$-rich matrices are pervasive in hydrothermal plume particles at the mid-ocean ridge (MOR) East Pacific Rise (EPR) $9^{\circ} \mathrm{N}$ at 2,504 $\mathrm{m}$ depth. The distribution and chemical speciation of $\mathrm{Fe}$ and $\mathrm{C}$ within small ( $\leqslant 10 \mu \mathrm{m}$ diameter) plume particles was examined by scanning transmission X-ray microscopy (STXM) and near-edge X-ray absorption fine-structure (NEXAFS) spectroscopy. The descending non-buoyant plume materials collected from Tica vent are very heterogeneous in size and composition, and contain high particulate organic carbon (POC) concentrations (for example, 6.7 wt\%) (Figs 1a,e, 2a-c and Supplementary Fig. S1, Table 1). We observed C-bearing particles and aggregates consisting of a wide variety of biological debris (megafaunal detritus, Supplementary Fig. S1) and exopolymericlike matrices with fibrous morphologies coating and aggregating particles (Figs 1f, 2a and Supplementary Fig. S6).

The presence of megafaunal detritus in plume-particle aggregates is consistent with the biologically active zone surrounding Tica vent in combination with the phenomenon of entrainment of near-vent sea water into the rising hydrothermal plume. However, the high organic $\mathrm{C}$ content and prevalence of exopolymer-like matrices in the vent particles was unexpected. In contrast to ultramafic-hosted hydrothermal venting, basalt-hosted vents such as those at EPR are not expected to produce large quantities of organic $C$ through abiotic synthesis ${ }^{11}$. In addition, deep-sea DOC is generally thought to be low in concentration and composed of fairly recalcitrant compounds. The exopolymer-like matrix observed here is composed of molecules that are quite labile-lipids, polysaccharides and proteins, as identified by C $1 s$ NEXAFS spectroscopy (see Fig. 2b, Supplementary Fig. S6 and the Methods section)-and are presumably in equilibrium with a dissolved fraction of equally labile compounds. Carbon $1 s$ NEXAFS spectra indicate that the POC is chemically heterogeneous at the nanometre scale, with composition consistent with mixtures of organic compounds (Fig. 2a,b and Supplementary Fig. S6). Consistent with a recent report on $\mathrm{Fe}(\mathrm{III})$-complexing ligands in non-buoyant plumes at the Mid-Atlantic Ridge $5^{\circ} \mathrm{S}$ (ref. 4), the presence of a biologically labile and chemically complex pool of organic $\mathrm{C}$ in the vicinity of hydrothermal venting at the EPR has implications

\footnotetext{
${ }^{1}$ Woods Hole Oceanographic Institution, Woods Hole, Massachusetts 02543, USA, ${ }^{2}$ Advanced Light Source, Lawrence Berkeley National Laboratory, Berkeley, California 94720, USA, ${ }^{3}$ Department of Biological Sciences, University of Southern California, Los Angeles, California 90089, USA. *Present address: Department of Soil, Water, and Climate, University of Minnesota-Twin Cities, St. Paul, Minnesota 55108, USA. †e-mail: toner@umn.edu.
} 

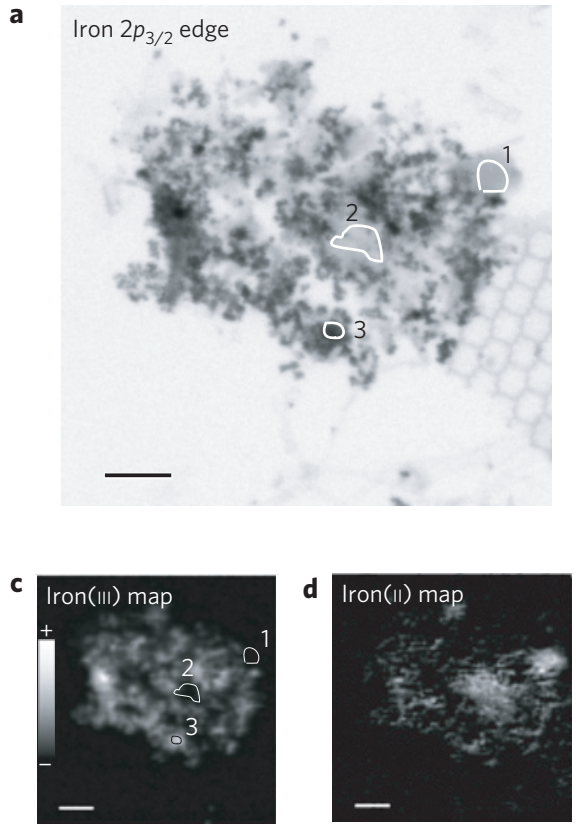

e Carbon map

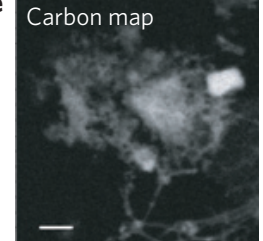

b
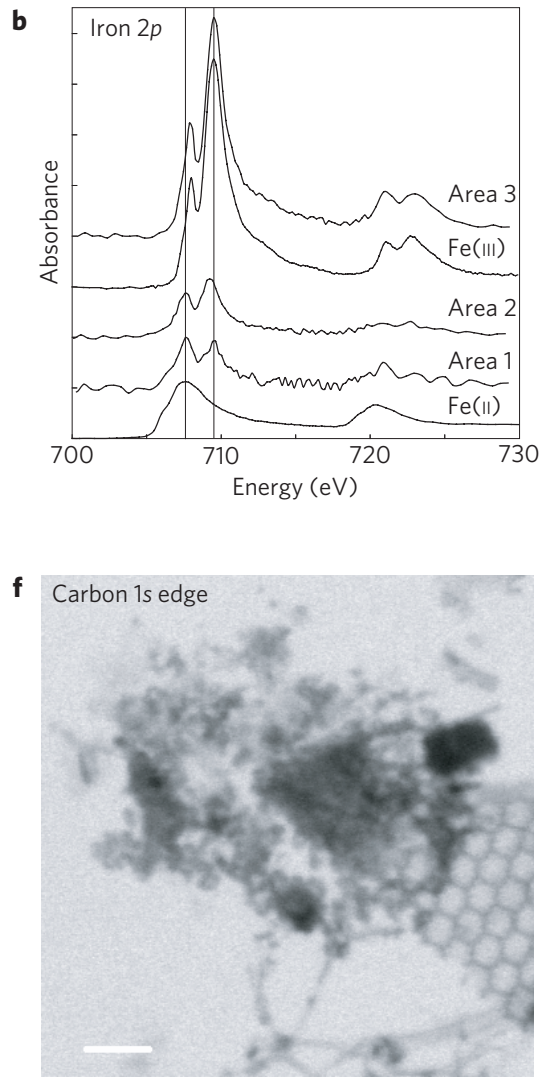

Figure 1 | Iron spectromicroscopy of a Tica vent aggregate showing Fe speciation and its association with C. a, STXM image recorded at the Fe $2 p_{3 / 2}$ edge ( $707.6 \mathrm{eV}$ ) showing three areas of interest (AOI) outlined in white. b, Iron NEXAFS spectra extracted from the three AOI presented with $\mathrm{Fe}(\mathrm{II})$ (pyrrhotite) and Fe(III) (ferrihydrite). Spectra from AOI 1 and 2 are multiplied by 4 and 2, respectively, for display purposes. c-e, Fe(III) (c), Fe(II) (d) and $\mathrm{C}$ (e) distribution maps. f, STXM image at the C 1s edge (300 eV). Scale bars are $1 \mu \mathrm{m}$.

for microbiological cycling and chemical speciation of important elements such as Fe.

The STXM images and Fe(II,III) maps shown in Fig. 1a,c-f demonstrate that Tica vent particles aggregate and these aggregates are mixtures of $\mathrm{Fe}(\mathrm{II})$ and $\mathrm{Fe}(\mathrm{III})$ : they also indicate that $\mathrm{Fe}$ (II), and to a lesser extent $\mathrm{Fe}(\mathrm{III})$, is co-located with the background organic matrix. The small, optically dense particles distributed throughout this representative aggregate are $\mathrm{Fe}(\mathrm{III})$-rich minerals (Fig. 1a, area 3). Although Fe 2p NEXAFS spectra cannot reveal the exact $\mathrm{Fe}$ (III) oxyhydroxide form, these minerals bear much spectral resemblance to Fe oxyhydroxides such as ferrihydrite (Fig. 1b) and goethite $^{12}$. Evenly dispersed $\mathrm{Fe}(\mathrm{II})$-rich materials largely dominate Fe speciation in certain areas of the aggregate (Fig. 1a, area 2). The evenly dispersed $\mathrm{Fe}$ associated with the organic matrix is consistent with either: (1) Fe in aqueous solution, (2) Fe in sorption complexes or (3) Fe in a uniformly distributed precipitate with a particle diameter much less than $30 \mathrm{~nm}$. We rule out dissolved Fe because the concentration would have to approach $0.1 \mathrm{mM}$ to be detected by STXM-NEXAFS (ref. 13). We can also exclude uniformly distributed nanoparticulate minerals on the basis of $\mathrm{Fe} 2 p$ NEXAFS spectra because the Fe(II) spectra (Fig. 1a, areas 1 and 2) do not match those of $\mathrm{Fe}(\mathrm{II})$-sulphide, -carbonate and -silicate minerals (Fig. 1b and Supplementary Fig. S5). In other words, the $\mathrm{Fe}(\mathrm{II})$ measured in those areas is not present as extremely finegrained pyrite, basalt glass or other typical Fe-bearing vent mineral fragments. Rather, the absence of discrete particles is consistent with a chemical association between $\mathrm{Fe}$ and $\mathrm{C}$ through sorption or complexation of $\mathrm{Fe}$ (II) to organic functional groups within the organic matrix. Therefore, the role of POC in Fe speciation could be analogous to aqueous Fe/organic ligand interactions.
Our characterization of the mineralogy of the Tica vent plume particles, using micro-focused X-ray diffraction and X-ray absorption spectroscopy, indicates the presence of $\mathrm{Fe}(\mathrm{III})$ oxyhydroxide minerals and a variety of sulphide minerals (see Supplementary Figs S2-S4). Although these observations are consistent with current thinking on the fate of hydrothermal $\mathrm{Fe}(\mathrm{II})$ in vented fluids, detection of $\mathrm{Fe}(\mathrm{II})$ in association with an organic matrix stands in stark contrast to this inorganic precipitation paradigm. To our knowledge, we are reporting the first observation of $\mathrm{Fe}$ (II) stabilized by POC in hydrothermal systems. Measurements of dissolved Fe(II) in the Arabian Sea oxygen minimum zone indicate that dissolved $\mathrm{Fe}(\mathrm{II})$ is only prevalent when dissolved oxygen concentrations are below $2 \mu \mathrm{M}$ (ref. 14). However, our samples were collected from oxygenated $\left(\sim 100 \mu \mathrm{M} \mathrm{kg}^{-1}\right)$ deep-ocean waters ${ }^{8}$ and stored in the presence of oxygen for $\sim 6$ months before analysis. The predicted half-life of $\mathrm{Fe}(\mathrm{II})$ at our sampling site is $3.5 \mathrm{~h}$ (ref. 8): suggesting that $\mathrm{Fe}(\mathrm{II})$ was stabilized against oxidation by molecular oxygen. We hypothesize that this stabilization may be due to complexation by organic matter produced by hydrothermal processes. Although many Fe-complexing organic compounds can enhance Fe oxidation rates, slow rates of $\mathrm{Fe}(\mathrm{II})$ oxidation in marine waters have been attributed to the presence of organic ligands ${ }^{15}$.

Strictly on the basis of available stability constant data for $\mathrm{Fe}(\mathrm{II})$-complexing organic ligands, organo-sulphur compounds such as 2,3-dimercaptopropanol $\left(\mathrm{C}_{3} \mathrm{H}_{8} \mathrm{OS}_{2}\right)$, with two thiol $(-\mathrm{SH})$ groups per molecule, are the best model candidates for $\mathrm{Fe}(\mathrm{II})$-stabilizing functional groups: $\log K$ values are 15.8 and 28.0 for the mono and bis complexes, respectively ${ }^{16}$. This compound also complexes $\mathrm{Fe}$ (III) with stability constants approximately equal to those for $\mathrm{Fe}(\mathrm{II})$, and our data do support the presence of 

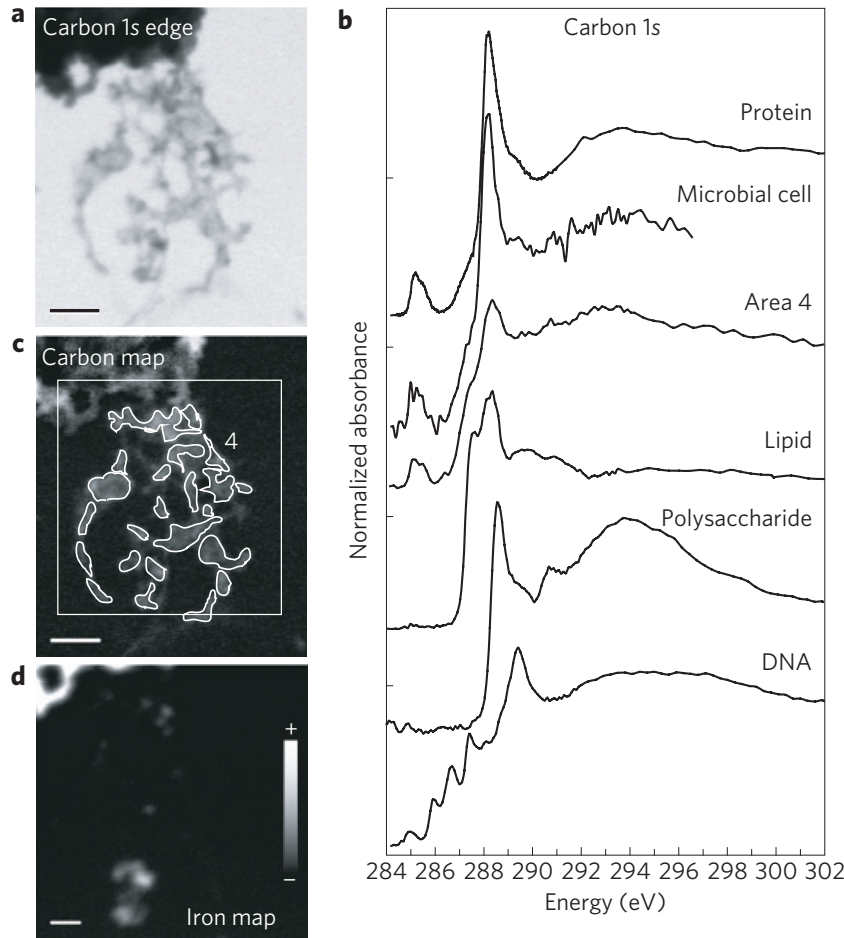

Figure 2 | Carbon spectromicroscopy of a Tica vent aggregate showing biomolecule signatures and association with Fe. a, STXM image recorded at the $\mathrm{C} 1 \mathrm{~s}$ edge $(300 \mathrm{eV})$. b, Carbon NEXAFS spectrum extracted from area of interest 4 outlined in white (c) along with reference spectra from protein (bovine serum albumin), a Tica vent microbial cell (see Supplementary Fig. S1), polysaccharide (alginate), nucleic acid (DNA) and lipid (1,2-dipalmitoyl-sn-glycero-3-phosphoethanolamine). c, Carbon distribution map. d, Iron distribution map from the white square area of the carbon map. Scale bars are $1 \mu \mathrm{m}$ for $\mathbf{a}-\mathbf{c}$ and $500 \mathrm{~nm}$ for $\mathbf{d}$.

$\mathrm{Fe}(\mathrm{III})$ associated with POC. We hypothesize that, at the EPR, organo-sulphur compounds form in the buoyant plume from mixing of $\mathrm{H}_{2} \mathrm{~S}$-rich vent fluids with entrained organic-rich waters derived from the biologically active sea floor in the vicinity of the vent. Our hypothesis is also supported by the fact that chemical reactions between $\mathrm{H}_{2} \mathrm{~S}$ and DOC have been shown to produce aggregates of polysaccharides and organo-sulphur compounds in marine surface waters ${ }^{17}$. In addition, Sander et al. ${ }^{5}$ have already proposed the presence of metal-reactive thiols in deep-sea hydrothermal fluids. At the EPR $9^{\circ} \mathrm{N}$, we may have the conditions necessary to produce flocculant organic materials and organo-S compounds: fluids have an excess of $\mathrm{H}_{2} \mathrm{~S}(\mathrm{~S} / \mathrm{Fe}$ ratio of 2.38:1; ref. 18) and near-vent bottom waters contain high POC concentrations (Table 1). Our hypothesis is testable through dynamic laboratory experiments that mix EPR endmember-like fluids with EPR near-vent bottom sea water or artificial sea water with specific DOC-POC characteristics. Furthermore, as nanoprobe extended X-ray absorption finestructure spectroscopy beamlines are developed, Fe $1 s$ measurements may provide extra information regarding the coordination environment of $\mathrm{Fe}$ (II) in the organic matrix.

Although few published data are available, several studies of DOC-POC in the vicinity of high-temperature venting provide evidence supporting our hypothesis that entrained, nearvent biological materials react with vent fluid constituents to form POC capable of stabilizing $\mathrm{Fe}$ (II) against oxidation. At the Endeavour ridge, greater than $95 \%$ of the $C$ measured within the first 21 vertical meters of a buoyant hydrothermal plume was identified as having a near-bottom biological origin ${ }^{19}$. More recently, measurements of DOC at the Juan de Fuca ridge have demonstrated elevated concentrations in some biologically productive areas of diffuse venting ${ }^{20}$. Dissolved organic ligands present in non-buoyant hydrothermal plumes at the Mid-Atlantic Ridge have been found to stabilize $\mathrm{Fe}(\mathrm{III})$ in solution (these complexes may represent $12-22 \%$ of the dissolved $\mathrm{Fe}$ in the deep ocean $)^{4}$. Furthermore, organic ligands with thiol functionality and stability constants high enough to compete with the precipitation of sulphide minerals have been proposed for hydrothermal fluids ${ }^{5}$.

The possible sources of DOC-POC to hydrothermal plumes may include: (1) abiotic synthesis in endmember fluids; (2) entrainment of near-vent biological materials such as megafaunal detritus, larvae and microbial mat materials, as well as vertical fluxes from the overlying water ${ }^{21}$; and (3) the presence and activity of microorganisms through input of exudates and cellular materials. For basalt-hosted systems such as the EPR, the biologically productive near-vent environment is probably the dominant source of both POC, as observed here, and DOC (ref. 4) to hydrothermal plumes.

The organic matrix we observe in EPR descending plume particles has an exopolymeric-like appearance (Fig. 2a), and may fit mechanistically into the DOC-POC continuum proposed generally for marine systems ${ }^{22,23}$. The EPR POC matrix bears strong spectral similarities to biological molecules-proteins, polysaccharides and lipids - which have also been identified, by wet chemical techniques, to form the building blocks of marine polymer gels elsewhere in coastal waters from Puget Sound and deep North Pacific and Arctic oceans ${ }^{24}$. Furthermore, both lipids ${ }^{25}$ and exopolymericlike matrices with spherical morphologies ${ }^{26}$ have been observed in hydrothermal plumes rising above the Juan de Fuca ridge, suggesting that our findings may be representative of general processes occurring at deep-sea hydrothermal vents.

The fate and transport of hydrothermal plume POC and its associated $\mathrm{Fe}$ is not known. However, long-distance transport of hydrothermally sourced particles from EPR has been demonstrated ${ }^{27-29}$. If we assume that colloidal particles with similar chemical composition are present in the migrating plume, then the long-lived presence of $\mathrm{Fe}(\mathrm{II})$ observed in these particles provides

Table 1 | Summary of mass flux, selected elemental composition, POC ${ }^{\star}$ and PIC $^{\dagger}$ for plume particles collected by sediment traps.

\begin{tabular}{|c|c|c|c|c|c|c|}
\hline & $\begin{array}{l}\text { Mass flux } \\
\mathrm{mg} \mathrm{m}^{-2} \mathrm{~d}^{-1}\end{array}$ & $\begin{array}{l}\text { Total Fe } \\
\text { wt } \%\end{array}$ & $\begin{array}{l}\text { Total Al } \\
\text { wt } \%\end{array}$ & $\begin{array}{l}\text { Total Mn } \\
\text { wt\% }\end{array}$ & $\begin{array}{l}\text { POC }^{\star} \\
\text { wt } \%\end{array}$ & $\begin{array}{l}\text { PIC }^{\dagger} \\
\text { wt } \%\end{array}$ \\
\hline Average (21-23 June 2006) & 10.8 & 2.69 & 0.67 & 0.08 & 6.70 & 4.99 \\
\hline Range (16 May-27 June 2006$)^{\S}$ & $8.3-29.9$ & $2.69-10.6$ & $0.67-1.29$ & $0.08-0.45$ & $6.39-10.6$ & $0.84-4.99$ \\
\hline
\end{tabular}

\footnotetext{
*Particulate organic carbon.

†'Particulate inorganic carbon.

Particles from this sediment trap collection bottle were used for mass flux and STXM measurements.

${ }^{\S}$ Reported figures represent the full range of values measured during sediment trap deployment.
} 
a possible mechanism for the escape of potentially bioavailable, hydrothermal $\mathrm{Fe}$ (II) from the immediate vicinity of the MOR crest-this is a testable assertion.

We hypothesize that Fe speciation at the EPR is linked to, and potentially controlled in part by, organic matter in the hydrothermal plume. Given the affinity of plume POC for Fe(II,III), the abundance of POC relative to Fe (Table 1), and the known metal-binding properties of POC produced in other environments (for example, humic substances, microbial biofilms and organic colloids), the POC we observe in the Tica vent plume may also contribute to the uptake of other important trace elements. Therefore, we propose a new and broader conceptual model for the source of reactive surfaces in hydrothermal plumes: one that includes plume organic matter in addition to the long-hypothesized $\mathrm{Fe}$ oxide particles. Our findings provide clear evidence that $\mathrm{Fe}$ and $\mathrm{C}$-cycling processes at MORs merit closer examination-both to improve our understanding of the biogeochemical cycle of Fe (a widely recognized limiting nutrient) and to better understand the impact of hydrothermal plumes on other trace element cycles in the oceans.

\section{Methods}

We examined descending, non-buoyant plume particles collected in sediment traps deployed $\sim 5 \mathrm{~m}$ above the sea floor $(\sim 2,500 \mathrm{~m}$ depth $)$ and $\sim 100 \mathrm{~m}$ west of Tica vent on the EPR using a McLane 21-position time-series trap deployed at $9^{\circ} 50.40^{\prime} \mathrm{N}, 104^{\circ} 17.52^{\prime} \mathrm{W}$. Samples were collected continuously, with each sample representing a two-day interval, from 16 May to 27 June 2006. Before deployment, each $250 \mathrm{ml}$ polyethylene sample cup was filled with dimethyl sulphoxide and buffered to $\mathrm{pH} 9.0 \pm 0.5$. This preservative stops all biological activity within the samples, retaining sample integrity for mineralogical, geochemical and molecular microbiological investigations ${ }^{30}$. On trap recovery, in early July 2006, each sample cup was capped and refrigerated at $4{ }^{\circ} \mathrm{C}$. Oxygen was not excluded during sample collection, storage, processing or analysis. Because biological activity was quenched by the dimethyl sulphoxide, we infer that the samples were in contact with dissolved oxygen concentrations between saturation (starting laboratory conditions) and the EPR ambient concentration of $\sim 100 \mu \mathrm{M} \mathrm{kg}^{-1}$ (ref. 8). For the spectral analyses, $10 \mathrm{ml}$ subsamples were drawn from each trap bottle under sterile conditions. Subsequently, all sample processing was conducted using standard methods established for sediment trap analyses ${ }^{31}$. Samples were sieved and the remaining $<1 \mathrm{~mm}$ fraction passed through a 10 -port rotating wet sediment splitter. Total dry mass for mass flux calculations was determined from three of the sample splits. 5-10 mg dried subsamples were analysed for particulate inorganic carbon, $\mathrm{POC}$, and $\mathrm{Al}, \mathrm{Ca}, \mathrm{Fe}$ and $\mathrm{Mn}$ using a $\mathrm{CHN}$ analyser and an inductively coupled plasma optical emission spectrometer, respectively.

The particle-by-particle mineralogy and Fe speciation in particles $\geqslant 10 \mu \mathrm{m}$ in diameter was characterized using micro-focused X-ray fluorescence, micro-focused Fe 1s X-ray absorption near-edge structure spectroscopy and micro-focused X-ray diffraction on beamline 10.3.2 of the Advanced Light Source (ALS), Lawrence Berkeley National Lab, Berkeley, California, USA. We identified inorganic Fe-bearing particles such as pyrite, 2-line ferrihydrite and basalt fragments (olivine and glass) (see Supplementary Figs S2-S4).

The STXM and NEXAFS spectroscopy measurements were carried out on the $<10 \mu \mathrm{m}$ size fraction at ALS beamlines 11.0.2 and 5.3.2. Transmission images at energies below and at the relevant absorption edges were converted into optical density images (optical density scales for Fig. 2c,d are $0-0.96$ and $0-1.63$, respectively) and used to derive elemental maps (optical density is equal to $\ln \left(I_{0} / I\right)$, where $I_{0}$ is the incident X-ray intensity and $I$ is the transmitted intensity through the sample). Approximately $1 \mu \mathrm{l}$ of rinsed plume particle suspension was deposited onto a $\mathrm{Si}_{3} \mathrm{~N}_{4}$ window (Silson Ltd). X-ray images and spectra were acquired in transmission mode using a scintillator-photomultiplier detector assembly. Image sequences, also called stacks, were recorded at energies spanning the $\mathrm{C} 1 s(280-320 \mathrm{eV})$ and $\mathrm{Fe} 2 p(700-730 \mathrm{eV})$ absorption edges and were used to generate NEXAFS spectra from pixel locations of interest. Iron and C NEXAFS spectra were compared with spectral libraries of reference compounds. Because Fe $2 p$ and C $1 s$ NEXAFS spectra are diagnostic of a specific Fe or C form in relation to reference spectra, our interpretation is limited by our reference spectral library and published spectra. As our reference libraries consist of many Fe-bearing minerals relevant to hydrothermal vent systems and $\mathrm{C}$ spectra relevant to biomolecules and natural organic matter, we have good confidence in our interpretation of the spectra. Pixel-by-pixel fitting of the stacks, using singular value decomposition, was used to create $\mathrm{Fe}$ (II) and $\mathrm{Fe}$ (III) distribution maps. All STXM data processing was carried out using the IDL package aXis2000 (ref. 32). To minimize radiation damage to the sample, spectra were collected from unique areas ( $\mathrm{C}$ and Fe stacks were never collected at the same location).
All measurements were carried out at ambient temperature and $\leqslant 1 \mathrm{~atm} \mathrm{He}$. The theoretical spatial and spectral resolutions of the beamlines were $40 \mathrm{~nm}$ and $\pm 0.1 \mathrm{eV}$, respectively. The presence and relative amplitude of the two $\mathrm{Fe} 2 p_{3 / 2}$ peaks is indicative of the relative proportions of $\mathrm{Fe}$ (II) (at $707.6 \mathrm{eV}$ ) and $\mathrm{Fe}$ (III) (at $709.5 \mathrm{eV}$ ) present in the areas of interest (AOI). The main Fe $2 p_{3 / 2}$ resonance of the reference mineral ferrihydrite, set at $709.5 \mathrm{eV}$, was used for relative energy calibration of the Fe spectra.

The main $\mathrm{C}$ functional groups in Tica vent POC were observed at (Fig. 2b and Supplementary Fig. S6): (1) $285.4 \mathrm{eV}$, common to proteins and consistent with $\mathrm{C} 1 s \rightarrow \pi_{\mathrm{C}=\mathrm{C}}^{*}$ of aromatic $\mathrm{C}$ rings ${ }^{33}$, (2) $287.4 \mathrm{eV}$, consistent with aromatic carbonyl and lipid signatures, (3) $288.2 \mathrm{eV}$, consistent with the $\mathrm{C} 1 \mathrm{~s} \rightarrow \pi_{\mathrm{C}=\mathrm{O}}^{*}$ of peptide bonds of protein molecules, (4) $288.4 \mathrm{eV}$, where the broad main resonance is centred consistent with carboxyl groups and (5) $288.7 \mathrm{eV}$, consistent with the $\mathrm{C} 1 \mathrm{~s} \rightarrow \pi_{\mathrm{C}=\mathrm{O}}^{*}$ signature of a polysaccharide component. The Rydberg transitions of gaseous $\mathrm{CO}_{2}$ at 292.74 and $294.96 \mathrm{eV}$ were used for calibration at the $\mathrm{C} 1 \mathrm{~s}$ edge.

\section{Received 4 June 2008; accepted 13 January 2009; published online 8 February 2009}

\section{References}

1. German, C. R. \& von Damm, K. L. Hydrothermal processes. Treatise Geochem. 6, 181-222 (2004).

2. Elderfield, H. \& Schultz, A. Mid-ocean ridge hydrothermal fluxes and the chemical composition of the ocean. Annu. Rev. Earth Planet. Sci. 24 191-224 (1996).

3. SCOR Working Group. SCOR GEOTRACES - An international study of the global marine biogeochemical cycles of trace elements and their isotopes. Chem. der Erde 67, 85-131 (2007).

4. Bennett, S. A. et al. The distribution and stabilisation of dissolved Fe in deep-sea hydrothermal plumes. Earth Planet. Sci. Lett. 270, 157-167 (2008).

5. Sander, S. G. et al. Organic complexation of copper in deep-sea hydrothermal vent systems. Environ. Chem. 4, 81-89 (2007).

6. Feely, R. A. et al. Composition and dissolution of black smoker particulates from active vents on the Juan de Fuca Ridge. J. Geophys. Res. 92, 11347-11363 (1987).

7. German, C. R., Campbell, A. C. \& Edmond, J. M. Hydrothermal scavenging at the Mid-Atlantic Ridge: Modification of trace element dissolved fluxes. Earth Planet. Sci. Lett. 107, 101-114 (1991).

8. Field, M. P. \& Sherrell, R. M. Dissolved and particulate Fe in a hydrothermal plume at $9^{\circ} 45^{\prime} \mathrm{N}$, East Pacific Rise: Slow Fe(II) oxidation kinetics in Pacific plumes. Geochim. Cosmochim. Acta 64, 619-628 (2000).

9. Statham, P. J., German, C. R. \& Connelly, D. P. Iron(II) distribution and oxidation kinetics in hydrothermal plumes at the Kairei and Edmond vent sites, Indian Ocean. Earth Planet. Sci. Lett. 236, 588-596 (2005).

10. Cowen, J. P., Massoth, G. J. \& Baker, E. T. Bacterial scavenging of Mn and Fe in a mid- to far-field hydrothermal particle plume. Nature 322, 169-171 (1986).

11. Shock, E. L. \& Schulte, M. D. Organic synthesis during fluid mixing in hydrothermal systems. J. Geophys. Res. 103, 28513-28527 (1998).

12. Chan, C. S. et al. Microbial polysaccharides template assembly of nanocrystal fibers. Science 303, 1656-1658 (2004).

13. Toner, B. et al. Spatially resolved characterization of biogenic manganese oxide production within the biofilm of Pseudomonas putida strain MnB1. Appl. Environ. Microbiol. 71, 1300-1310 (2005).

14. Moffett, J. W., Goepfert, T. J. \& Naqvi, S. W. A. Reduced iron associated with secondary nitrite maxima in the Arabian Sea. Deep-Sea Res. 54, 1341-1349 (2007).

15. Millero, F. J., Sotolongo, S. \& Izaguirre, M. The oxidation kinetics of Fe(II) in seawater. Geochim. Cosmochim. Acta 51, 793-801 (1987).

16. Martell, A. E. \& Smith, R. M. Critical Stability Constants Vol. 3: Other Organic Ligands (Plenum Press, 1989).

17. Ciglenecki, I. et al. The role of reduced sulfur species in the coalescence of polysaccharides in the Adriatic Sea. Mar. Chem. 71, 233-249 (2000).

18. Feely, R. A., Gendron, J. F., Baker, E. T. \& Lebon, G. T. Hydrothermal plumes along the East Pacific Rise, $8^{\circ} 40$ to $11^{\circ} 50$ : Particle distribution and composition. Earth Planet. Sci. Lett. 128, 19-36 (1994).

19. Roth, S. E. \& Dymond, J. Transport and settling of organic material in a deep-sea hydrothermal plume: Evidence from particle flux measurements. Deep-Sea Res. 36, 1237-1254 (1989).

20. Lang, S. Q. et al. Dissolved organic carbon in ridge-axis and ridge-flank hydrothermal systems. Geochim. Cosmochim. Acta 70, 3830-3842 (2006).

21. Honjo, S., Manganini, S. J., Krishfield, R. A. \& Francois, R. Particulate organic carbon fluxes to the ocean interior and factors controlling the biological pump: A synthesis of global sediment trap programs since 1983. Prog. Oceanogr. 76, 217-285 (2008).

22. Verdugo, P. et al. The oceanic gel phase: A bridge in the DOM-POM continuum. Mar. Chem. 92, 67-85 (2004).

23. Engel, A. et al. Polysaccharide aggregation as a potential sink of marine dissolved organic carbon. Nature 428, 929-932 (2004).

24. Chin, W.-C., Orellana, M. V. \& Verdugo, P. Spontaneous assembly of marine dissolved organic matter into polymer gels. Nature 391, 568-572 (1998). 
25. Wakeham, S. G., Cowen, J. P., Burd, B. J. \& Thomson, R. E. Lipid-rich ascending particles from the hydrothermal plume at Endeavour Segment, Juan de Fuca Ridge. Geochim. Cosmochim. Acta 65, 923-939 (2001).

26. Shackelford, R. \& Cowen, J. P. Transparent exopolymer particles (TEP) as a component of hydrothermal plume particulate dynamics. Deep-Sea Res. I 53, 1677-1694 (2006).

27. Lyle, M. W. Major element composition of Leg 92 sediments. Initial Reports of the Deep Sea Drilling Project Vol. 92, 355-370 (1986).

28. Lupton, J. E. Hydrothermal helium plumes in the Pacific Ocean. J. Geophys. Res. 103, 15853-15868 (1998).

29. Feely, R. A. et al. Hydrothermal plume particles and dissolved phosphate over the superfast-spreading southern East Pacific Rise. Geochim. Cosmochim. Acta 60, 2297-2323 (1996).

30. Comtet, T. et al. Molecular and morphological identification of settlement-stage vent mussel larvae, Bathymodiolus azoricus (Bivalvia: Mytilidae), preserved in situ at active vent fields on the Mid-Atlantic Ridge. Limnol. Oceanogr. 45, 1655-1661 (2002).

31. Honjo, S., Dymond, J., Collier, R. \& Manganini, S. J. Export production of particles to the interior of the equatorial Pacific Ocean during the $1992 \mathrm{EqPac}$ experiment. Deep-Sea Res. 42, 831-870 (1995).

32. Hitchcock, A. P. <http://unicorn.mcmaster.ca/aXis2000.html>.

33. Myneni, S. C. B. in Applications of Synchrotron Radiation in Low-Temperature Geochemistry and Environmental Science Vol. 49 (eds Fenter, P. A.,

Rivers, M. L., Sturchio, N. C. \& Sutton, S. R.) (The Mineralogical Society of America and The Geochemical Society, 2002).

\section{Acknowledgements}

We thank D. Adams, S. Beaulieu, S. Mills, B. Govenar and T. Shank for trap deployment/collection; J. P. Cowen, K. Von Damm, A. Thurnherr (NSF Ridge 2000), L. Mullineaux, J. Ledwell and A. Thurnherr (NSF OCE BIO and PO) for cruise berths; C. S. Chan for STXM standards; and ALS BL 10.3.2 users for Fe K-edge XAS reference spectra. Financial support: NASA Postdoctoral Program (B.M.T.), NSF OCE 0425737 (K.J.E. and J.W.M.), WHOI DOEI (L. Mullineaux, O.R., C.R.G. and K.J.E.), NSF OCE 0648287 (K.J.E., C.R.G. and O.R.) and NSF OCE 0424953 (L. Mullineaux). The Advanced Light Source is supported by the Office of Science, Basic Energy Sciences, Division of Materials Science of the US Department of Energy under contract No. DE-AC02-05CH11231.

\section{Author contributions}

Manuscript preparation, ALS beamtime proposals and spectroscopy data collection-analysis-interpretation (B.M.T); spectroscopy data collection-analysis-interpretation (S.C.F.), inductively coupled plasma optical emission spectrometry measurements (S.J.M.); spectroscopy data collection (C.M.S.); mineralogy data analysis (M.A.M.); project planning, data interpretation and mentoring (K.J.E, C.R.G, O.R., J.W.M) 